\title{
Testing the convergent and discriminant validity of three implicit motive measures: PSE, OMT, and MMG
}

\author{
Julia Schüler $^{1}$ - Veronika Brandstätter ${ }^{2} \cdot$ Mirko Wegner $^{1} \cdot$ Nicola Baumann $^{3}$
}

Published online: 7 June 2015

(C) Springer Science+Business Media New York 2015

\begin{abstract}
Implicit motive research has shown that implicit motives are important predictors of behavior and well-being. However, little is known about the interrelationship between the different implicit motives measures frequently applied. We aimed to shed light on the convergent validity of three implicit motive measures and wanted to test their assumed statistical independence from three explicit motive measures. Therefore, we administered the picture story exercise (PSE), the operant motive test (OMT), and the multi-motive grid in one and the same study. As explicit measures, we used the personality research form, the motive enactment test, and a goal questionnaire. We investigated the statistical overlaps between all these measures (sample: 202 undergraduate students) and found that the implicit motive measures showed either no or only little correlation with each other. Furthermore, they also partly correlated with explicit motive measures. Supplementary analyses showed that the lack of statistical overlap between PSE and OMT can partly be ascribed to their different scoring systems.
\end{abstract}

Keywords Implicit motives $\cdot$ Explicit motives $\cdot$ Motive diagnostic

Julia Schüler

julia.schueler@ispw.unibe.ch

1 Department of Sport Science, University of Bern, Fabrikstrasse 8, 3012 Bern, Switzerland

2 University of Zurich, Zurich, Switzerland

3 University of Trier, Trier, Germany

\section{Introduction}

Since McClelland et al. (1989) made the distinction between an implicit and an explicit motivational system, numerous studies have used these concepts to predict a variety of outcome variables (Baumann et al. 2005; Brunstein and Schmitt 2004; Hagemeyer and Neyer 2012; Hofer and Chasiotis 2003; Hofer et al. 2006; Job et al. 2009, 2010; Kazén and Kuhl 2011; Kehr 2004; Schultheiss et al. 2004; Schüler et al. 2010; Wegner and Schüler 2014; Woike et al. 2003). However, these studies are quite heterogeneous with regard to which implicit motive measures they employed. In the present research, we investigated the statistical overlap between three implicit motive measures: the picture story exercise (PSE; Schultheiss and Pang 2007), which is a further development of the thematic apperception test (TAT; Murray 1943), the operant motive test (OMT; Kuhl and Scheffer 1999), and the multi-motive grid (MMG; Sokolowski et al. 2000). Furthermore, we examined their relationships with questionnaires, which are often used to measure the explicit motivational system: the personality research form (PRF; Jackson 1984), the Motive Enactment Test (MET; Kuhl 1999), and a goal questionnaire (Goal; Job et al. 2009).

\section{Implicit motives and their differentiation from explicit motives}

Motive researchers have mainly focused on three motives. The achievement motive (McClelland et al. 1953) is conceptualized as the "capacity to derive satisfaction from the autonomous mastery of challenging tasks" (Schultheiss 2008, p. 603, see also McClelland et al. 1953). It represents the desire to perform better than before, to have successful interactions with one's environment, and to meet and 
exceed high standards of excellence. The affiliation motive is conceptualized as the "capacity to derive satisfaction from establishing, maintaining, and restoring positive relationships with others" (Schultheiss 2008, p. 605; see also Atkinson et al. 1954). It represents the desire to spend harmonious time with others and to make friends. The power motive is conceptualized as the "capacity to derive pleasure from having physical, mental, or emotional impact on other individuals or groups of individuals [...]" (Schultheiss 2008, p. 606, see also Winter 1973). It represents the desire to influence other persons, and gain and maintain reputation and prestige.

Motives were measured either using a projective measure derived from the thematic apperception test, originally presented by Murray (1943), or using questionnaires. However, the different motive measures were statistically independent, which led McClelland et al. (1989) to postulate two independent motivational systems: implicit and explicit motives.

Implicit and explicit motives differ in terms of the incentives, which elicit the motives, whereby implicit motives are aroused by affective incentives promising rewarding emotions, and explicit motives are aroused by rational incentives, including social expectations. They also differ in the resulting behavior, with implicit motives predicting spontaneous behavioral trends over time and explicit motives predicting immediate responses to specific situations, often based on cognitively elaborated decisions. McClelland and colleagues (McClelland 1980; McClelland et al. 1989) called the former "operant behavior" and the latter "respondent behavior".

An important difference between implicit and explicit motives is the way they are assessed. Because implicit motives are conceptualized as being non-conscious, they have to be measured indirectly via the coding of imaginative stories in response to pictorial stimuli. Implicit motive measures capture participants' operant behavior by assessing freely generated responses to open response formats. The theoretical background is the apperception assumption of motive measurement, according to which pictorial stimuli elicit previous experiences with motiverelated themes (e.g., affiliation, power, achievement) and therewith affect the interpretation of the displayed scenes. In order to allow for the process of apperception and capture implicit motives (rather than self-attributed motives), it is important not to ask a person to describe him- or herself as having the motive, but ask to interpret other persons' feelings, thoughts, and behavior displayed in pictures (e.g., Brunstein and Maier 2005; McClelland et al. 1989; Schultheiss et al. 2009; Spangler 1992). The most frequently used implicit measures which fulfill the important criteria of motive arousal through pictures and the evaluation of other people rather than oneself are described in detail below.

In contrast, explicit motives are self-attributed, cognitively accessible motives and thus can be measured directly using self-reports. Examples are questionnaires such as the personality research form (PRF, Jackson 1984), the Motive Enactment Test (MET, Kuhl 1999), and different measures for assessing personal goals (Brunstein et al. 1998; Job et al. 2009). A common feature of most explicit motive measures is that participants rate pre-formulated items according to whether or how well the statements fit them, using restricted response formats (rating scales). In terms of McClelland (1980), respondent (response) behavior is captured. Whereas the questionnaires are quite similar in nature, the implicit motive measures differ significantly, especially in their response formats and the way in which the motives are scored (see examples of implicit motive measures below).

Empirical evidence confirmed the theoretical considerations regarding the predictive power of implicit motives and their differentiation from explicit motives in a broad range of domains. In order to illustrate the variety of dependent variables previously used, we highlight some past studies on the predictive value of implicit motive measures. The implicit achievement motive, for example, predicted the amount of income 30 years later (McClelland and Franz 1992; implicit motive measure, IMM: PSE), better professional positions (Andrews 1967; IMM: PSE), performance on a math task (Biernat 1989; IMM: PSE), but not the choice to be the group leader in another task (choices are predicted by explicit achievement motive). It predicted performance on a scrambled-word task but not whether participants attributed achievement-related traits to themselves (deCharms et al. 1955; IMM: PSE). The implicit achievement motive is also associated with entrepreneurial activity (McClelland 1965; IMM: PSE), whereas explicit motive measures failed to predict managerial success. It furthermore predicted performance in a reaction task (Puca and Schmalt 1999; IMM: MMG) and correlated with response latencies in a Stroop task when stimuli were presented subliminally, but not, when presented supraliminary (Langens and Dorr 2006; IMM: MMG). The implicit achievement motive was associated with intrinsic motivation (Schüler 2007; IMM: MMG) and the implicit, but not the explicit achievement motive interacted with the corresponding basic need for competence (according to Self-Determination Theory, Deci and Ryan 1985) to predict intrinsic motivation and flow experience (Schüler et al. 2010; IMM: MMG). Components of the more differentiated OMT implicit achievement motive measure (pressure to achieve, coping with failure) predicted grades at university courses in stressful learning situations (Scheffer 2005; IMM: OMT). 
In a study by Schultheiss and Brunstein (2002; IMM: PSE), the implicit power motive predicted nonverbal behavior but not verbal arguments in a persuasion task. The component "prosocial power" of the OMT power motive scoring predicted leadership competencies assessed in an assessment center procedure (Scheffer 2005; IMM: OMT). Earlier studies showed the implicit power motive to be related with preference for objects of prestige and competitive sports (Winter 1973; IMM: PSE). Furthermore, implicit power and achievement motives predicted the content of daydreaming activity whereas explicit motives did not (Schmalt and Langens 1996; IMM: MMG).

With regard to the affiliation motive the implicit but not the explicit motive predicted the frequency of social contacts (McAdams and Constantian 1983). The amount of intimacy contents in picture stories, for example, predicted marital happiness 17 years later (McAdams and Vaillant 1982). The implicit affiliation motive was also associated with an increase in progesterone level after motive arousal (Schultheiss et al. 2004; IMM: PSE) and implicit affiliation and power motivation depend on the stage of the menstrual cycle (Schultheiss et al. 2003; IMM: PSE). As far as the authors know no comparable findings for the explicit motives exist. Implicit affiliation, but not explicit affiliation motive predicted intuitive thought (Quirin et al. 2013a; IMM: OMT) and implicit affiliation predicted sensitivity towards social cues such as human faces (Schultheiss and Hale 2007; IMM: PSE; Atkinson and Walker 1956). Moreover, implicit motives influenced accessibility to past emotional experiences whereas explicit motives were linked to accessibility of memories relevant to the selfconcept (Woike et al. 2003; IMM: PSE).

Summing up briefly, previous research has convincingly shown that implicit motives are important predictors of cognitive processes, motivation, and behavior and can be empirically differentiated from explicit motives. However (as we have indicated in parentheses), implicit and explicit motives were so far assessed using different measures. In the following we will outline commonly used implicit motive measures one after the other.

\section{Three examples of implicit motive measures}

Previous research has made several attempts to assess implicit motives (Heckhausen 1963a, b; Heyns et al. 1958; McClelland et al. 1953; Veroff 1957). ${ }^{1}$ In the following, we

\footnotetext{
${ }^{1}$ Besides the picture story exercise (PSE), the operant motive test (OMT), and the multi-motive-grid (MMG) described in detail below, a few other promising methods have been developed. For example, domain-specific measures exist such as the partner-related agency and communion test (PACT; Hagemeyer and Neyer 2012), which assesses implicit communal motives, the Achievement Motive Grid (Schmalt 1999), and the affiliation motive grid (Sokolowski 1992), which are
}

will describe the PSE, OMT, and MMG in detail because they fulfill the most important characteristics of an implicit motive measure (see above: implicit motive arousal through pictures and description of other persons instead of oneself), because they have often been used as implicit motive measures, and because they have been shown to predict operant behavior reliably.

\section{The picture story exercise (PSE)}

The precursor of the picture story exercise, as it is used in current research, is the thematic apperception test developed by Morgan and Murray (1935) and Murray (1943). Influenced by the psychoanalytic principle of projection, it is assumed that people are unable to consciously access most of their wishes and desires, but that these can be brought out when individuals freely write stories allegedly unrelated to themselves.

Implicit motive research agrees in principle with the assumption that individuals often do not know the origin of their emotions and behavior, and thus cannot be asked directly to report their motives (McClelland et al. 1953, 1989, for a summary see Schultheiss and Pang 2007). Therefore, ambiguous pictorial stimuli are used to stimulate a person's implicit motives, which will then be expressed in the person's written story. The PSE instructions include guiding questions (e.g., What is happening? Who are the people? What happened before? What are the people thinking about and feeling? What do they want? What will happen next?), but participants were informed that these are only guides to invent their stories and that they do not have to answer them specifically. Participants are asked to write whatever story comes to their mind. Therewith, the PSE provides an open response format, which allows for a spontaneous response in a situation that is relatively unstructured. In other words, it is able to elicit operant behavior in participants (McClelland 1980). The PSE procedure is illustrated in Fig. 1. For a step-by-step guide to measuring implicit motives using the PSE (e.g., test administration, coding), see Schultheiss and Pang (2007).

Several theoretically and empirically derived coding systems have been developed to analyze participants' stories for motive content (see Smith et al. 1992; Winter

Footnote 1 continued

precursors of the MMG. Furthermore, the implicit association test (IAT, Greenwald et al. 1998), based on response latency technique, has successfully been used to assess implicit motives (Brunstein and Schmitt 2004; Slabbinck et al. 2011). Another behavior-based test for assessing achievement motivation is the objective achievement motivation test (Schmidt-Atzert 2004). Here, participants have to navigate a winding road by pressing two keys on the keyboard. The test performance serves as measure of achievement motivation. 
open response format of PSE

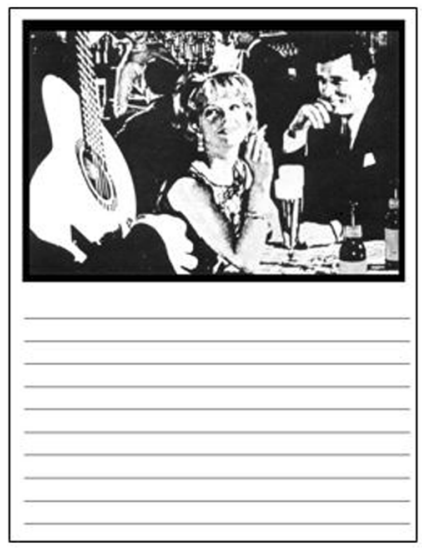

partly-restricted response format of OMT

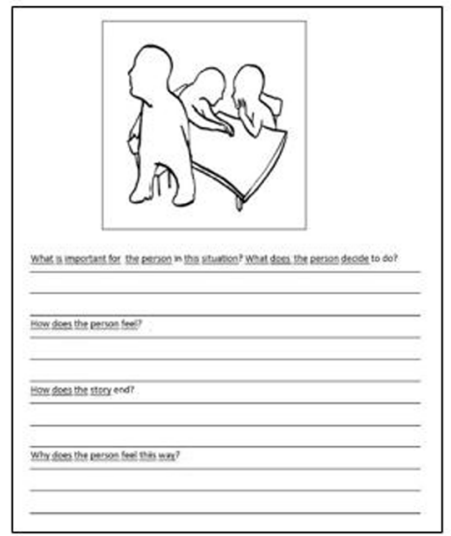

restricted response format of MMG

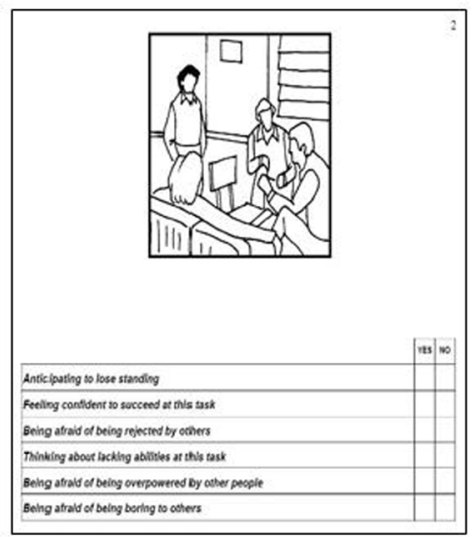

Fig. 1 Illustration of the response formats of the picture story exercise (PSE) (left), the operant motive test (OMT) (in the middle), and the multimotive-grid (MMG) (right)

1999). Because Winter's (1994) scoring manual for running texts has often been used in current motive research, we have stated its scoring categories in Table 1. As can be seen, the achievement and affiliation scoring categories contain hope as well as fear components of the motives (Ach: PSE 4, Aff: PSE 2). Aside from the specific contents to be coded, the coding manual (Winter 1994) lists further coding rules (e.g., a story can be scored for more than one motive and one motive can be scored several times) that have to be followed.

The PSE is the oldest and most often-used approach to assess implicit motives (among the three motive measures we are discussing in this paper). Much research has been done which convincingly provides empirical evidence for different kinds of validity (e.g., sensitivity towards motive arousal, predictive validity, discriminant validity).

One important validity criterion of an implicit motive measure is its sensitivity to motive arousal, which has been shown in the early stage of the development of the PSE coding systems. Here, motives were aroused in participants through suitable motivational arousal conditions and the content of their picture stories were compared to groups of participants whose motives were not experimentally aroused (see Winter 1999). More up to date studies showed that the PSE-measured affiliation, power and achievement motives predict affective responses to incentives (e.g., Fodor et al. 2006), direct attention (e.g. Schultheiss and Hale 2007), support motive-related goal striving (e.g., Brunstein and Maier 2005), are associated with health outcomes (e.g., Jemmott 1987; McClelland 1979; McClelland et al. 1980, 1987) and were shown to have physiological correlates (power: testosterone level, e.g., Schultheiss et al. 2005; affiliation: progesterone level, e.g., Schultheiss et al. 2003; achievement: release of peptide hormone arginine-vasopression, McClelland 1995). With regard to convergent validity, Spangler's (1992) metaanalysis showed that the TAT and questionnaires were only moderately correlated and predict different kinds of outcome variables. For further evidence for PSE's validity see Schultheiss (2008).

Summing up, the PSE is a theoretically well-based and trusted measure of implicit motives with a broad basis of studies that demonstrate its validity. However, the PSE has also disadvantages that do not encourage researchers to engage in implicit motive research. A practical disadvantage is that applying the PSE (recommended: participants write stories to six pictures which take about $5 \mathrm{~min}$ each; Schultheiss and Pang 2007) and coding the stories content is very time-consuming (estimation of time needed for each story: 2-5 min; Schultheiss and Pang 2007). Furthermore, motive coding requires a high expertise that can only be achieved by a time-consuming learning process of how to code motives in running texts using training materials and by additionally coding more than 1000 stories (Schultheiss and Pang 2007). A theoretical disadvantage of the PSE is that most coding systems either assess all three motives without differentiating into their hope and fear components (Winter 1994) or assess hope and fear components of just one motive (e.g., Uleman 1972: power; Veroff 1957: power; Heckhausen 1963a, b: achievement; Birney et al. 1969: affiliation). If a researcher is interested in the hope and fear components of all three motive (because he or she might be interested in the highly topical field of approach and avoidance motives and motivation) he or she must apply more than one coding system. For the reason of overcoming these disadvantages two research groups have developed alternative measures (OMT, MMG) that will be introduced in the following paragraphs. 
Table 1 Categories of the PSE (Winter 1994; left-hand column) and OMT (Kuhl and Scheffer 1999; right-hand column) scoring systems

\begin{tabular}{|c|c|c|}
\hline & PSE categories & OMT categories \\
\hline Ach & $\begin{array}{l}\text { PSE 1: Adjectives that positively evaluate performance } \\
\text { PSE 2: Goals or performances described in ways that suggest positive evaluation } \\
\text { PSE 3: Mention of winning or competing with others } \\
\text { PSE 4: Failure, doing badly or other lack of excellence* } \\
\text { PSE 5: Unique accomplishment }\end{array}$ & $\begin{array}{l}\text { OMT 1: Flow, curiosity, interest } \\
\text { OMT 2: Inner standards of excellence, } \\
\text { teamwork } \\
\text { OMT 3: Coping with failure } \\
\text { OMT 4: Pressure to achieve, social standards } \\
\text { OMT 5: Fear of failure, self-criticism* }\end{array}$ \\
\hline Aff & $\begin{array}{l}\text { PSE 1: Positive friendly feelings towards other persons } \\
\text { PSE 2: Sadness or negative feeling about separation or disruption of a friendly } \\
\text { relationship, or wanting to restore it* } \\
\text { PSE 3: Affiliative, companionate activities } \\
\text { PSE 4: Friendly nurturing acts }\end{array}$ & $\begin{array}{l}\text { OMT 1: Intimacy, relatedness, affective } \\
\text { sharing } \\
\text { OMT 2: Sociability, extraverted contact } \\
\text { OMT 3: Coping with rejection, networking } \\
\text { OMT 4: Affiliation, avoiding insecurity } \\
\text { OMT 5: Fear of rejection, dependence* }\end{array}$ \\
\hline Pow & $\begin{array}{l}\text { PSE 1: Strong, forceful actions which inherently have impact on other people } \\
\text { PSE 2: Control or regulation } \\
\text { PSE 3: Attempt to influence, persuade, convince, make or prove a point, argue } \\
\text { PSE 4: Giving help, advice or support that is not explicitly solicited } \\
\text { PSE 5: impressing others or the world at large: mention of fame, prestige and reputation } \\
\text { PSE 6: eliciting strong emotional responses in others. }\end{array}$ & $\begin{array}{l}\text { OMT 1: Guidance, prosocial leadership } \\
\text { OMT 2: Status, having prestige and authority } \\
\text { OMT 3: Coping with power-related threats, } \\
\text { self-assertiveness } \\
\text { OMT 4: Direction/dominance or inhibited } \\
\text { power } \\
\text { OMT 5: Fear of being powerless, submission* }\end{array}$ \\
\hline
\end{tabular}

Scoring categories representing fear components of motives are marked by an asterisk

Ach achievement, Aff affiliation, Pow power

\section{The operant motive test (OMT)}

The operant motive test (Kuhl and Scheffer 1999) is also theoretically based on Murray's (1943) TAT, but has been methodologically and theoretically extended in several respects. In the OMT, participants are presented with ambiguous pictorial stimuli too (see Fig. 1b). One methodological development is that participants are asked to make up a story about a main character in each picture but do not then write entire stories about the pictures, but instead briefly answer four questions displayed along with each picture. The questions refer to the main character: "What is important for the person in this situation and what is the person doing? How does the person feel? Why does the person feel this way? How does the story end?". In contrast to the open response format of the PSE, the OMT's response format can best be described as partly open. The pictures presented are line drawings (see Fig. 1b).

The most important theoretical innovation is that, in addition to the three motive contents, five implementation strategies for satisfying motives are distinguished. This 3 (motive contents) $\times 5$ (implementation strategies) coding scheme allows for insights into more complex personality system interactions as postulated by Kuhl (2001). Whereas four implementation strategies represent the hope components of the motives (crossing affective source and type of motivation: positive affect, self-regulated; positive affect, incentive based; negative affect, self-regulated; negative affect, incentive based), the fifth strategy (low positive affect, high negative affect) represents the motives' fear components. The scoring categories are also displayed in Table 1. For a detailed description of further scoring rules, see Kuhl and Scheffer (1999).

Extensive research on the OMT has been published in Baumann et al. (2005, 2010), Scheffer (2005), Scheffer et al. (2003), and in Kuhl et al. (2003). Evidence for the OMTs predictive validity was found for all three motives in various contexts. To name but a few examples, Chasiotis and Hofer (2003) found an achievement sub-category (achievement flow) to be related with number of school years and level of education. Achievement flow also predicted daily flow experience (Baumann and Scheffer 2010) and educational attainment in different cultures (Busch et al. 2013). In a study by Wegner and Teubel (2014), the OMT achievement motive predicted different sport behavior (match performance) than the explicit achievement motive (choices for goal distances) in team sports. Scheffer et al. (2003) showed OMT-achievement motive to be related with grades in university and the power motive to be associated with success in assessment center tasks for managers. As theoretically predicted, Baumann et al. (2010) reported associations between the positively 
charged intrinsic components of the power and affiliation motive scoring categories and intuitive self-access as measured by short latencies during a self-evaluation task (cf. Koole and Jostmann 2004). Further evidence for the OMT's affiliation motive was provided by Scheffer et al. (2003) who found the OMT affiliation motive associated with early interpersonal binding. Wegner and colleagues showed that the affiliation motive predicted nonverbal behavior in sports competition (Wegner et al. 2014a) and moderated cortisol responses to acute psychosocial stress in high school students (Wegner et al. 2014b). In accordance with the assumption that individuals with high affiliation scores want to be liked, Scheffer et al. (2007) found that the OMT-affiliation motive predict customer service orientation of trainees of various international companies positively. Also studies testing the theoretically-expected differentiation between implicit (OMT) motives and explicit measures of personality and their interplay speak in favor of the OMT's validity (e.g., Aydinli et al. 2014; Job et al. 2010; Kazén and Kuhl 2011; Quirin et al. 2013b). Analyses of OMTs convergent validity revealed inconsistent results. For example, significant correlations between OMT scores and corresponding TAT scores were found in a Cameroonian subsample but not in other subsamples (German, Costa Rican) of Chasiotis and Hofer's (2003) studies. Supporting the OMT's sensitivity towards motive arousal, Scheffer et al. (2007, Study 1$)^{2}$ found that the OMT-affiliation score could be predicted in an affiliation motive arousal procedure (as proposed by Shipley and Veroff 1952). The PSE-affiliation score, however, could only be predicted marginally in this study.

Summing up, previous research provided empirical support for the validity of the OMT (see also Baumann et al. 2010; Scheffer et al. 2003). However, many fewer studies have been published with regard to its predictive validity and sensitivity towards motive arousal than for the traditionally older PSE.

\section{The multi-motive grid}

The multi-motive grid is a semi-projective measure, which aims to use the advantages of previous implicit and explicit motive measures simultaneously (Langens and Schmalt 2009; Sokolowski et al. 2000). It is introduced to participants as a task in which they have to evaluate everyday situations displayed in pictures (e.g., rope climber, work group, people taking an exam, athletes playing tennis) (see Fig. 1c). Referring to the principle of the TAT, these pictures are assumed to arouse implicit motives. However, in contrast to the TAT, participants do not write entire stories

\footnotetext{
$\overline{2}$ The study by Scheffer et al. (2007) was originally designed to test a more complex interaction effect.
}

about the pictures (which have to be scored by researchers in an elaborate and time-consuming procedure), but instead respond to a set of statements (as in explicit questionnaire measures) which are presented along with the pictures. These statements represent emotional responses (e.g., "feeling confident to succeed at this task" for the achievement motive), needs (e.g., "hoping to get in touch with other people" for the affiliation motive) and instrumental acts (e.g., "trying to influence other people" for the power motive) which cover contents typically generated in the picture story exercise (for a detailed description of the development of the MMG, see Langens and Schmalt 2009; Sokolowski et al. 2000). Participants rate whether or not the statements fit the situations displayed in the pictures.

Because combining the different picture situations (a) with the set of statements $(b)$ result in a grid consisting of $a \times b$ cells, this measurement technique is also called grid technique (Sokolowski et al. 2000; see also previous grid measures, e.g., Hurley 1955).

Hence, the MMG provides a restricted response format. Furthermore, the MMG allows hope and fear components of each motive to be measured (achievement: hope of success and fear of failure; affiliation: hope of affiliation and fear of rejection, power: hope of power and fear of power) in detail and thereby directly addresses an important distinction made in research on motivation (Lewin 1935; McClelland 1985). Participants' answers can easily be aggregated to form six motive scores (hope and fear components of the three motives). An illustration of the MMG is given in Fig. 1c.

The validity of the MMG as an implicit motive has been shown in previous studies (Gable et al. 2003; Kehr 2004; Langens and Schmalt 2002, 2009; Puca 2005; Puca et al. 2006; Schüler et al. 2008).With regard to its predictive validity, for example, Puca et al. (2006) showed that strength of MMG's avoidance motives predicted forceful avoidance movements (moving arm backwards), Puca and Schmalt (1999) showed that the hope component of the achievement motive predicted enjoyment in a challenging reaction time task better than fear of failure. Langens and Schmalt (2002) found MMG motives related to content of daydreaming and behavioral indicators of motivation (Langens 2003). Hope and fear components of the power motive predicted emotional responses to sexual infidelity (Esters 2006, see also Schmalt 2006). Gable (2006) found hope of affiliation to be related with less loneliness and fear of rejection as associated with more loneliness. Further studies showed that MMG motives moderate the relationship between challenge-skill-balance and flow experience (Schüler 2007) and moderate the effects of an emotional writing intervention on well-being (Langens and Schüler 2005). For further evidence for MMG validity see Langens and Schmalt (2009) and Sokolowski et al. (2000). 
However, there are some inconsistent results with regard to some aspects of the MMG's validity. For example, in some studies no significant correlations with explicit motive measures were found (e.g., Schmalt and Langens 1996; Schüler 2010; Schüler et al. 2008) but in other studies a moderate degree of convergence with explicit motive measures was revealed (e.g., Kehr 2004). Furthermore, as far as the authors know, studies demonstrating that motive arousal (through an experimental manipulation) leads to corresponding changes in MMG scores (sensitivity to motive-arousal) are missing so far. Summing up, although previous studies mainly support the validity of the MMG, there are still a few inconsistencies that have to be addressed in future research. Furthermore, the number of studies providing empirical support for the MMG's validity is much smaller than the broad empirical basis that demonstrates the PSE's validity.

\section{What do the three implicit motive measures have in common and what differentiates them?}

Summing up the previous paragraphs, the motive scores of the PSE, OMT, and MMG emanated from different developmental approaches. Although the number of studies supporting their validity differs, all three measures have been shown to being able to predict outcome variables that are in line with theoretical assumptions. Nevertheless, they partly differ in terms of the theoretical considerations on which scale development is based. PSE and MMG refer to Murray (1938) and McClelland (1985) who agreed that human motivation results from a limited amount of human needs (later called implicit motives), which interact with incentives in the environment and that the assessment of implicit motives requires motive arousal by pictorial (rather than verbal) stimuli. The MMG furthermore allows to measure hope and fear components of all three motives and therewith Atkinson's differentiation into a motive's approach and avoidance tendencies can be considered easiest (e.g., without learning different coding systems).

In contrast, the OMT is additionally based on Personality System Interaction Theory (Kuhl 2001) and therewith aims to capture different implementation strategies for satisfying motives. However, this more differentiated measurement approach also allows to aggregate scores and therefore enables the measurement of overall implicit achievement, affiliation, and power motives.

The aim of the present research was to focus on the methodological differences between PSE, OMT, and MMG. The three measures for implicit motives can be compared with respect to the stimulus material, the instructions for generating a response, the response format, and the coding system used for coding the responses. One important similarity between the PSE, OMT, and MMG is that they provide pictures which stimulate the implicit motives. This is based on a core motivational principle, according to which motives have to be aroused, for example by external pictorial cues, to come into effect (Heckhausen and Heckhausen 2008; McClelland 1985). Pictures - in contrast to verbal material (e.g., statements in questionnaires)-automatically activate affective networks, consisting of past experiences that relate to real-life situations, and therefore elicit similar motivational responses to those that would be expected in real life. By using pictures, another thing that all three implicit motive measures have in common is that they allow for the process of apperception (i.e., need-related interpretation of perceptual input) so that motive-related knowledge rooted in prelinguistic affective experiences in early states of development can contribute to the participants' responses (cf. Baumann et al. 2010). However, the pictures presented in the PSE, OMT, and MMG differ with regard to the situations displayed and the type of picture used-photographs (most PSE pictures) or line drawings (OMT, MMG).

Although the three implicit motive measures have in common that participants are asked to evaluate other people's feelings, behavior, and thoughts rather than one's own they differ in the extent to which they stimulate identification processes. Whereas the PSE asks subjects to write stories about persons displayed in pictures (see above for guiding questions) and the MMG asks them to respond to statements, which refer to pictures often depicting more than one person, the OMT focuses participants' attention to one person by instructing them to write stories about a main character displayed in the picture.

Another important difference between the three implicit motive measures is how they capture participants' responses to the pictures. The PSE procedure asks them to freely invent and write down entire imaginative stories and support this process by providing guiding questions; the OMT procedure asks them to answer pre-formulated questions; and the MMG procedure asks them to agree or disagree with pre-formulated questionnaire items. These differences in the openness versus restrictiveness of the response formats lead to different ways of computing the motive scores. Whereas the MMG motive scores are easily calculated by summing up corresponding items, the PSE stories and OMT text materials have to be analyzed using specific coding systems (PSE: Winter 1994; OMT: Kuhl and Scheffer 1999) which differ with respect to their scoring categories and scoring rules. For further deliberation and argument about the differences between the administration format of the OMT, MMG and PSE see also Thrash et al. (2007) and Schultheiss et al. (2009). 


\section{Present research}

Previous research has shown that implicit and explicit motive measures were unrelated (McClelland et al. 1989). But how strongly are implicit motive measures related among each other? Only a few studies have tested correlations between single implicit motive measures so far. These studies showed for example a lack of variance overlap between PSE with motive grid (Brunstein 2008) and with measures which are methodologically similar to the MMG (Schultheiss et al. 2009). As far as the authors know, the three implicit motive measures PSE (Schultheiss and Pang 2007), OMT (Kuhl and Scheffer 1999), and MMG (Sokolowski et al. 2000) have not been used simultaneously in a single study with the same participants. We therefore administered all three motive measures to a sample of undergraduate students and additionally assessed explicit motives using a German version of the PRF (Stumpf et al. 1985), the MET (Kuhl 1999) and a goal measure (Job et al. 2009). We used the measure-specific motive scoring procedures of the PSE, OMT, and MMG. In supplementary analyses, outlined in the results section, we coded stories produced within the PSE procedure using the OMT scoring system. ${ }^{3}$ In doing this, we aimed to examine the role of the different coding systems in the statistical overlap between the PSE and OMT.

Referring to the theoretical conceptualization of implicit motives (Brunstein 2008; McClelland 1985; Schultheiss and Brunstein 2010; Spangler 1992) and the differentiation into an implicit and explicit motivational system (McClelland et al. 1989), we hypothesized that the implicit motive measures are significantly correlated with each other, whereas they are unrelated to explicit motive measures. Furthermore, also the explicit motive measures were expected to be significantly related.

\section{Methods}

\section{Participants and procedure}

Participants were recruited using a mass mailing to students of the University of Zurich and by advertising for the web-survey

\footnotetext{
3 We applied Winter's (1994) scoring rule, according to which several motives can be scored for one story and one motive can be scored several times. When applying the OMT scoring rule, which says that the written material for each picture should only be scored for one motive, we got very similar results. The means for these achievement, affiliation and power motive were $1.78(S D=1.07)$, $2.12(S D=.85), 1.76(S D=1.14)$. These scores correlated significantly with the scores reported in the text (achievement: $r=.74$, $p<.001$; affiliation: $r=.51 p<.001$; power: $r=.81, p<.001)$ and additionally were significantly related to the corresponding PSE scores (achievement: $r=.54, p<.001$; affiliation: $r=.42, p<.01$; power: $r=.13, n s)$.
}

study in lectures. They filled in two web surveys at an interval of 2 weeks in return for extra course credit. Out of the 210 participants who filled in the first questionnaire, 202 participants (174 women, mean age of 22.13 years, $S D=5.14$, age range $18-53$ years) also filled in the second questionnaire. Participants who decided to quit the study did not differ in any of the assessed variables assessed in the first questionnaire. The questionnaires contained the three implicit and three explicit motive measures, as well as further variables, which are of no interest for the present research question. We controlled for different orders of implicit and explicit motive measures (e.g., two implicit and one explicit motive measure in the first web survey, and one implicit and two explicit measures in the second web survey, and vice versa).

\section{Implicit motive measures}

\section{Picture story exercise}

We administered the picture story exercise following the guidelines suggested by Schultheiss and Pang (2007) to assess the implicit achievement, affiliation, and power motives. Participants were asked to write an imaginative story about each of six pictures (boxer, women in a laboratory, ship captain, couple by the river, trapeze artists, nightclub scene), which were displayed successively on the computer screen. Participants were instructed to include information on who the people in the pictures are, what they are thinking and feeling, and how the story will end. Each picture was presented for $15 \mathrm{~s}$. Afterwards participants had 4 min to write their story. They were then asked to finish their story and continue with the next picture.

Scores for the implicit achievement, affiliation, and power motive were obtained using Winter's (1994) scoring system, as described above. Two experienced raters (agreement of 95 and $97 \%$ with materials prescored by Winter 1994) coded the achievement, affiliation and power motive independently of each other and achieved a high interrater reliability (the intraclass correlation coefficients for achievement, affiliation, and power were. $80, .89, .87)$. Non-agreements were solved by discussion. Participants had an average score for the achievement motive of $6.26(S D=2.92$; range from 0 to 14; Cronbach's Alpha $\left.=.38^{4}\right)$, 6.15 for the affiliation

\footnotetext{
${ }^{4}$ The internal consistency scores for the PSE (Cronbach's Alpha between .38 and .44) and for the OMT (Cronbach's Alpha between .10 and .52) are low (see also Schultheiss et al. 2008). However, as Schultheiss et al. (2008) summarized, internal consistency coefficients are not a suitable criterion to evaluate implicit motive measures' reliability (e.g., because the interplay between a stable motive and stable incentive cue in the pictures give rise to variable motive expression from one response to pictorial stimuli to the other; see also dynamics of action theory; Atkinson and Birch 1970). A more suitable criterion of reliability is the inter-rater reliability, which is sufficiently high for the PSE and OMT.
} 
motive $(S D=2.65$; range from 1 to 18 ; Cronbach's Alpha $\left.=.35^{4}\right)$ and 5.66 for the power motive $(S D=3.96$; range from 0 to 23; Cronbach's Alpha $=.44^{4}$ ). The motive scores were significantly positively correlated with the number of words in the stories (all $p s<.001$ ) and therefore the raw scores were residualized for the sum of the words using linear regression. In the following, we will refer to these residualized scores as PSE-Ach, PSE-Aff and PSEPow. We used histograms and the Kolmogorov-Smirnov Test (KS) that showed that the word-count corrected motive scores are normally distributed (PSE-Ach: KS $z=.038$, $d f=202, p=.20 ;$ PSE-Aff: KS: $z=.035, d f=202$, $p=.20$; PSE-Pow: KS: $z=.059, d f=202, p=.09$ ).

\section{Operant motive test}

The operant motive test (OMT, Kuhl and Scheffer 1999) was administered according to the recommendations of the authors of the test. We presented 15 line drawings along with the four guideline questions (see paragraph The Operant Motive Test) to which participants provided their spontaneous associations by making brief notes.

Two well-trained coders (different from the PSE coders) independently scored the implicit achievement, affiliation, and power motives, using the OMT scoring manual (Kuhl and Scheffer 1999). The sums across all 5 categories (implementation strategies) were computed for each motive (achievement: $M=2.72, S D=1.30$, range from $0-5$, Cronbach's $\quad$ Alpha $=.10^{4} ; \quad$ affiliation: $\quad M=2.91$, $S D=1.34$, range from 0 to 6 , Cronbach's Alpha $=.29^{4}$; power: $M=7.57, S D=2.12$, range from 0 to 12 , Cronbach's Alpha $=.52^{4}$ ).

The interrater agreement was high (achievement: $r=.90, p<.001$, affiliation: $r=.94, p<.001$, power: $r=.92, p<.001)$. Non-agreements were solved by discussion. The abbreviations for the resulting scores are OMT-Ach, OMT-Aff, and OMT-Pow. Histograms and KSTests showed that the motive scores were not normally distributed (OMT-Ach: KS: $z=.19, d f=202, p=.001$; OMT-Aff: KS: $z=.14, d f=202, p=.001$; OMT-Pow: $\mathrm{KS}: z=.12, d f=202, p=.001)$. Because deviation from normal distribution could not be corrected using squareroot or log transformations we used rank correlations to analyze the relationship between the variables (see below).

\section{Multi-motive grid}

We used the multi-motive grid (MMG, Sokolowski et al. 2000) as introduced above. As recommended in the test author's manual, we presented 14 pictures along with statements referring to the persons displayed in the line drawings (e.g., achievement: "Feeling good about one's competence", affiliation: "Feeling good about meeting other people", power: "Hoping to acquire a good standing"). In order to capture hope as well as fear components of the motives (as in the PSE and OMT), we summed up participants' agreements with statements representing the hope components hope of success (HS, $M=7.05$, $S D=2.04$, range 2-12, Cronbach's Alpha $=.60)$, hope of affiliation (HA, $M=5.59, S D=1.82$, range $2-10$, Cronbach's Alpha $=.63)$, hope of control $(\mathrm{HC}, M=7.91$, $S D=2.29$, range 2-12, Cronbach's Alpha $=.62$ ) as well as the fear components fear of failure (FF, $M=4.74$, $S D=2.20$, range $2-12$, Cronbach's Alpha $=.61$ ), fear of rejection (FR, $M=5.86, S D=2.39$, range $2-11$, Cronbach's Alpha $=.61)$, fear of control (FC, $M=6.46$, $S D=2.60$, range $2-11$, Cronbach's Alpha $=.62$ ) of each motive. We aggregated the motives scores (MMGAch $=$ HS plus FF; MMG-Aff: HA plus FR; MMGPow = HP plus FP). Using only the hope components rather than these aggregated scores did not significantly change the results reported below. ${ }^{5}$ Histograms and $\mathrm{KS}$ Tests showed that the MMG motive scores were not normally-distributed (HS/FF KS: $z=.114 / .108, d f=202$, $p=.001$; HA/FR: KS: $z=.118 / .117, d f=202, p=.001$; HC/FC: KS: $z=.139 / .113, d f=202, p=.001$; MMGAch: $z=.09, d f=202, p=.001 ;$ MMG-Aff: $z=.08$, $d f=202, \quad p=.001 ; \quad$ MMG-Pow: $z=.10, \quad d f=202$, $p=.001)$.

\section{Explicit motive measures}

\section{Personality research form $(P R F)$}

The personality research form was originally developed to assess 20 different facets of personality (e.g., aggression, endurance, impulsivity). Because the subscales achievement, affiliation, and dominance fit the theoretical conceptualization of the achievement, affiliation, and power motive very well, the scales have often been used as explicit motive measures (Brunstein and Maier 2005; Kehr 2004; Schüler 2010). Besides the English original version (Jackson 1984), a German version of the PRF (Stumpf et al. 1985) also exists. The achievement scale (e.g., "My goal is to do at least a little bit more than anyone else has done before"), the affiliation scale (e.g., "I spend a lot of

\footnotetext{
5 When correlating the hope components of each motive measure (OMT scores without categories 5, PSE without achievement category 4 and affiliation category 2, MMG hope scores; for OMT and PSE fear categories see Table 1) rather than using the aggregated score (hope plus fear), the correlation pattern is quite similar. The correlations between the OMT and PSE are an exception. The correlation between OMT-Ach and PSE-Ach changed from $r=.12$, ns (as reported in Table 2) to $r=.18, p<.05$. The correlation between OMT-Aff and PSE-Aff increased from $r=.10$, ns to $r=.18, p<.05$. However, the OMT-Pow and PSE-Pow correlation was no longer significant, $r=.04$, ns (rather than $r=.15, p<.05$ ).
} 
time visiting my friends"), and the dominance scale (e.g., "I try to control others rather than permit them to control me") consist of 16 items each and utilizes a true/false response scale. Scores for the explicit achievement motive (PRF-Ach, $M=10.00, S D=2.44$, range 4-15, Cronbach's Alpha $=.54$ ), affiliation motive (PRF-Aff, $M=11.90, \quad S D=2.95, \quad$ range $2-16, \quad$ Cronbach's Alpha $=.73$ ) and power motive (PRF-Pow, $M=7.56$, $S D=3.64$, range $0-16$, Cronbach's Alpha $=.78$ were computed by summing up the items participants had agreed with (versus those rejected). The aggregated scores were not normally distributed (PRF-Ach: KS: $z=.110$, $d f=202, p=.001$; PRF-Aff: KS: $z=.160, d f=202$, $p=.001$; PRF-Pow: KS: $z=.077, d f=202, p=.005)$.

\section{Motive enactment test (MET)}

The motive enactment test (Kuhl 1999) consists of 60 items with twelve items (four items per scale) representing the explicit achievement motive (e.g., "I often volunteer to solve difficult tasks" $) \quad(M=1.41, \quad S D=.31$, range $.63-2.38$, Cronbach's Alpha = .62), affiliation (e.g., "Being close to other people is more important to me than being successful") $(M=1.88, S D=.31$, range 1.08-2.60, Cronbach's Alpha = .75), and power motives (e.g., "Other people often prefer me to be the leader") $(M=1.36$, $S D=.34$, range $.55-2.40$, Cronbach's Alpha $=.76)$. Participants are asked to rate their agreement with each of the statements using a rating scale ranging from 1 (not at all) to 4 (very much). The mean was computed for the achievement (MET-Ach), affiliation (MET-Aff), and power (METPow) motive. Histograms and KS-Tests that showed that the MET motive scores are normally distributed (METAch: KS: $z=.050, d f=202, p=.20$; MET-Aff: KS: $z=.054, d f=202, p=.20$; MET-Pow: KS: $z=.059$, $d f=202, p=.09)$.

\section{Goal measure}

Participants rated a list of 15 goals according to how strongly they feel committed to each goal, using a 9-point rating scale (1: not committed at all to 9: very committed). The goals were selected as the most typical goals for students, based on pilot studies in which university students were asked to write down their personal goals (cf. Job et al. 2009; Schnelle et al. 2010). The goal questionnaire contains five achievement goals (e.g., "I want to perform better than is expected of me"), five affiliation goals (e.g., "I want to get to know my fellow students personally"), and five power goals (e.g., "I want to appear self-confident to the other students"). Scores for achievement goals (GOAL-Ach), $(M=4.96, S D=1.05$, range $1.60-7.00$, Cronbach's Alpha $=.80$ ), affiliation goals (GOAL-Aff),
$(M=5.16, \quad S D=1.20, \quad$ range $1.00-7.00$, Cronbach's Alpha $=.83)$, and power goals (GOAL-Pow), $(M=4.52$, $S D=.95$, range $1.40-6.60$, Cronbach's Alpha $=.66)$ were computed by averaging the answers over the five items. The GOAL motive scores were not normally distributed (GOAL-Ach: KS: $z=.062, d f=202, p=.050$; GOALAff: KS: $z=.073, d f=202, p=.012$; GOAL-Pow: KS: $z=.121, d f=202, p=.001)$.

\section{Results}

\section{Preliminary analyses, descriptive statistics and correlations}

Participant's age did not influence the results reported below. Women and men did not differ in the result pattern reported below. Correlational analyses (Spearman, twotailed) were computed to analyze the relationship between and within the implicit and explicit motive measures. Table 2 displays the correlations among all the variables assessed. We used bold type to highlight the correlations between the implicit motive measures within one motive theme, which we hypothesized to be significantly positively related. We used italics to highlight the correlations between implicit and explicit motives within one motive theme, which were theoretically expected to be unrelated.

Among the implicit motive measure scores (see correlations in upper left quadrant of Table 2), unexpectedly, only two out of nine correlations were significantly correlated, although correlations were very small. The PSE and MMG affiliation scores as well as the PSE and OMT power scores were significantly related, with $r=.14, p<.05$ and $r=.15, p<.05$, respectively. Furthermore, several significant intercorrelations between the three motives were observed within each motive measure (PSE: correlations between $r=-.15$ and $.19, p<.05$; OMT: two significant correlation of $r=.24, p<.01$; MMG: correlations between $r=.40$ and $.44, p<.001)$.

Among the explicit motive measure scores, all expected correlations were significant and in the predicted direction (see correlations in lower right quadrant of Table 2), ranging from $r=.22, p<.05$ to $r=.46, p<.001$. However, also moderate intercorrelations between motives within motive measures (that is correlations between motives) were observed (PRF: correlations between $r=.16, p<.05$ and $.26, p<.01$; MET: correlations between $r=.25$ and $r=.41, p<.01$; Goals: correlations between $r=.21, p<.05$ and $r=.54, p<.001)$. Table 2 also shows the correlations between implicit and explicit motive measure scores, which we hypothesized to be unrelated. As can be seen from the correlations in the upper right quadrant of Table 2, out of the 27 correlations testing 


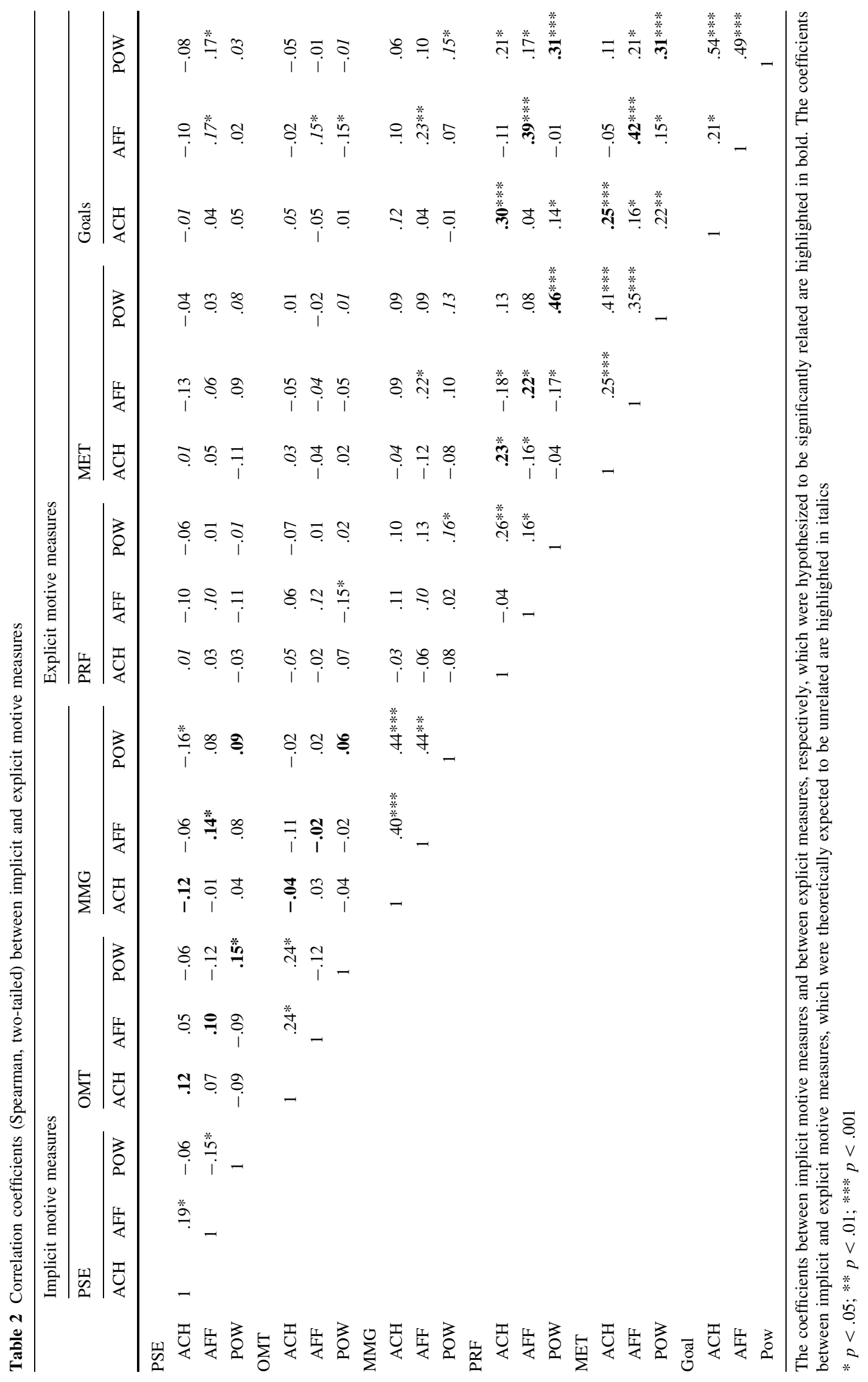


for an association between the implicit-explicit measures of the motives, 6 correlations were significant (achievement: 0 out of 9 correlations, affiliation: 4 out of 9, power: 2 out of 9). More specifically, all three implicit affiliation motive score measures were significantly related with the explicit affiliation goal measure (PSE: $r=.17, p<.05$; OMT: $r=.15, p<.05$; MMG: $r=.23, p<.01)$. Furthermore, the MMG affiliation score was related to MET affiliation $(r=.22, p<.05)$ and MMG power was related to PRF and Goal power scores $(r=.16, r=.15$, $p$ 's $<.05)$.

\section{Supplementary analysis}

The unexpected low correlations between the implicit motive measures prompted us to conduct a further analysis. It is based on the following rationale. As mentioned above, the implicit motive measures differed in the type of picture used (PSE: photographs, MMG, OMT: line drawings), the instruction to identify with a main character (OMT: present, PSE, MMG: absent), their response formats (MMG: restricted, OMT: partly open, PSE: open), and in their coding systems (MMG: no coding system required, OMT: Kuhl 1999, PSE: Winter 1994). Thus, low correlations between motive measures can be traced back to the different pictures, the different instructions regarding the identification processes, the different response formats, the different coding systems, or to all of the distinguishing features. In order to thoroughly figure out the role of each distinguishing feature, the features need to be combined systematically as much as possible (e.g., combining PSE's story-writing with OMT scoring categories and MMG pictures).

With the present data, we can only make a first attempt and test a small part of these combinations. We estimated the role of PSE's and OMT's response formats and coding systems in the lack of statistical overlap by applying one and the same coding system to the partly open as well as to the open response format. We therefore applied the OMT scoring system to the written material produced by the OMT's partly open response format (original procedure as described above) and, in addition, applied it to the stories written with the PSE's open-response format (these new scores are referred to in the following as OMTPSE-Ach, OMTPSE-Aff, OMTPSE-Pow). ${ }^{6}$ The pictures were kept constant. Histograms and KS- Tests showed that the newlygenerated motive scores were not normally-distributed

\footnotetext{
6 The reader might wonder why we did not additionally code the OMT-generated text material using the PSE scoring system. We tried to do this, but failed due to the fact that the PSE scoring rules and categories are designed for "running texts" (title of Winter's coding manual, Winter 1994) and do not seem to be applicable to texts in note form. We would be interested in other authors' experiences with similar attempts.
}

(OMTPSE-Ach: $\quad \mathrm{KS}: \quad z=.16, \quad d f=50, \quad p=.004$; OMTPSE-Aff: KS: $z=.13, d f=50, p=.027$; OMTPSEPow: KS: $z=.12, d f=50, p=.05)$. We therefore again used rank correlations for the following analyses.

What do these newly-generated motive scores mean? What they have in common with the original PSE scores (PSE-Ach, PSE-Aff, PSE-Pow) is that they are based on an open response format (stories) and on the same set of pictures. They differ from the original PSE scores in terms of their scoring systems. Thus, if we correlate the new scores with the original PSE scores, this amounts to changing the scoring systems while holding the response format and pictures constant. The strength of the new correlations can then be interpreted as the amount of similarity between the OMT and PSE coding systems. The deviations from the possible maximum of $r=1.0$ can be interpreted as differences between the coding systems.

Two independent raters (one experienced PSE rater and one well-trained OMT rater) coded the picture stories of 50 randomly chosen participants using the OMT scoring manual. In order to adapt the OMT scoring system to the fact that more complex stories rather than brief notes were coded, we allowed each story to be coded for more than one motive. ${ }^{7}$ The interrater agreements between the coders were satisfactorily high, with .86 for achievement, .95 for affiliation, and .85 for power.

The correlation coefficients (Spearman, two-tailed) between the newly generated motive scores and the original PSE scores are significant, with $r=.71, p<.001$ for the achievement motive $(M=4.44, S D=2.30), r=.38$, $p<.01$ for the affiliation motive $(M=6.02, S D=1.94)$, and $r=.26, p<.10$ for the power motive $(M=4.88$, $S D=2.41)$. Hence the determination coefficients are $R^{2}=.50, R^{2}=.14$ and $R^{2}=.07$, respectively. In other words, the similarity between the scoring systems accounts for a proportion of variability in our data set of $50 \%$ for the achievement motive, $14 \%$ for the affiliation motive and $7 \%$ for the power motive. ${ }^{8}$

\section{Discussion}

Whereas it is consensus in motive research, that implicit and explicit motive measures are unrelated (McClelland et al. 1989), less research has tested so far whether different measures of implicit and explicit motives, respectively,

\footnotetext{
7 See footnote 3 .

${ }^{8}$ The newly-generated achievement motive score correlated with the OMT achievement with $r=.08, n s$ and with the MMG achievement score $r=.03, n s$. The correlations between the newly-generated affiliation (power) motive scores were $r=-.05, n s(r=.23, n s)$ for the OMT and $r=.25, p<.10(r=.21, n s)$ for the MMG scores.
} 
were related with each other. With our study, we aimed to test the convergent validity of three frequently-used measures of implicit motives: the PSE, OMT, and MMG. In addition, we examined their discriminant validity by assuming a non-overlap between implicit and explicit measures (PRF, MET, goal measure). We therefore used coders who were trained in laboratories with different motive measure traditions (OMT coders from Baumann's lab, PSE coders from Brandstätter's lab and Schüler's lab) in order to guarantee a sophisticated and unbiased motive scoring. We expended a lot of effort on test application and motive coding. However, our analyses mainly revealed theoretically unexpected results.

First, the correlations among the implicit motive measures were very low: Only 2 out of 9 correlations between corresponding implicit motive measures were significant. To be more precise, the MMG affiliation motive correlated with the PSE affiliation motive $(r=.14, p<.05)$, and the OMT power score correlated with the corresponding PSE score, $r=.15, p<.05$. One reason for low correlations between measures which are theoretically expected to assess the same concept could be that one or more measures do not assess implicit motives. However, previous research has already shown empirical evidence for the validity of all three measures. However, the empirical evidence is much stronger for the PSE (Schultheiss and Pang 2007) than for the OMT (Baumann et al. 2005; Scheffer et al. 2003) and MMG (Langens and Schmalt 2009; Sokolowski et al. 2000).

Another reason for the low correlations between the implicit motive measures are their different characteristics, i.e. the different pictures, different instructions regarding identification processes, different response formats, and different scoring systems. From our data we could only make a first attempt to disentangle the role of the PSE's and OMT's different scoring systems in the lack of statistical overlap. Supplementary analyses showed that when the same scoring system is applied to text material generated by an open response format (PSE stories) and by a partly open response format (OMT notes) the common variances for the three motive themes are $50 \%$ (achievement), $14 \%$ (affiliation), and $7 \%$ (power). Putting this differently, 50, 86 and $93 \%$ (differences from $100 \%$ ) of the variance are explained by variables other than the scoring systems (e.g., pictures, identification instruction, response format). However, also this statement has to be taken with care: As can be seen, the statistical correspondences are uneven for the three motives. The coding system explains a much greater amount of the statistical overlap for the achievement motive than for the affiliation and power motive. This might also be due to different degrees of similarity in coding categories of the OMT and PSE procedure which in turn can be traced back to differences in theoretical approaches on which the scoring rules are based (see introduction).

Critically considered, our supplementary analyses are based only on a single study and urgently need to be replicated. Furthermore, an important future aim is to figure out to what statistical degree the other aspects of the measurement (e.g., different pictures, person-perspective, theoretical formulation) would contribute to greater statistical correspondence. It could also help to apply scoring systems to the PSE stories which differentiate into hope and fear components of motives (e.g., Heckhausen 1963a, b) in order to better adjust the procedure of analyses for the PSE, OMT and MMG.

A second unexpected result was that the intercorrelations between motive scores within one measure were higher than the correlations of the same motives between the motive measures. This is particularly obvious for the OMT (highest within-method correlation: $r=.24$, highest between-method correlation: $r=.15$ ) and MMG (highest within-method correlation: $r=.44$ highest betweenmethod correlation: $r=.14$ ) and to a lesser degree for the PSE (highest within-method correlation: $r=.19$, highest between-method correlation: $r=.15$ ). Thus, although all three implicit motive measures strongly refer to the concept of implicit motives in the McClelland (1985) tradition, the unique methodological character of each measure was stronger than the common theoretical basis.

A third unexpected result was that implicit and explicit motive scores were partly related. The PSE, OMT, and MMG affiliation scores were all significantly related to the affiliation goal measure. This is in accordance with previous research showing higher (although non-significant) correlations between implicit and explicit motive measures for the affiliation domain, $r=.13$ ) than for the achievement, $r=.06$, and power domain, $r=.04$ (Schultheiss and Brunstein 2001) or even low significant relationships between implicit and explicit affiliation motive measures $(r=.16$; Langan-Fox and Canty $2010 ; r=.21$; Schultheiss et al. 2009). This leads us to the question whether the implicit affiliation motive might be more easily accessible to the conscious mind, or easier to translate into explicit self-concepts than the achievement or power motive, for example due to its high social desirability or due to the fact that people's explicit understanding of affiliation is closer to affects (enjoying time with others, feelings of warmth and harmony) than our explicit understandings of power and achievement, which are more strongly directed towards the environment (influencing other people, showing high performance) rather than towards a person's feelings.

Furthermore, the MMG motive scores correlated with the corresponding PRF, MET, and the goal measure scores. It seems that its methodological similarity to questionnaires (restricted response format) leads to a partial statistical 
overlap with explicit motive measures. Although the participants are not asked to refer the MMG statements to themselves, but to the situations displayed in the MMG pictures, each statement has to be cognitively evaluated, which might disturb the spontaneous and affective responses associated with implicit motives. In other words, the MMG might capture participants' (response) behavior (agreement, not agreement) in clearly-structured situations (statements), which could be better interpreted as respondent rather than operant behavior, in the terminology of McClelland (1980). Summing up, the MMG shares characteristics with implicit motive measures (motive arousal through pictures, apperception, and contribution of preconceptual representations) as well as with explicit motive measures (restricted response format and contribution of conceptual representations) and this might be the reason why it also shares variance with both types of measures.

Another point of criticism is that the explicit motive measures also showed high intercorrelations (up to $r=.54$, $p<.001)$ within each measure, which exceeded the correlations between corresponding coefficients between the measures. Thus, the measurement of the explicit motives and hence the test of convergent validity also needs to be optimized.

\section{Limitations of the present study}

The major limitation of the present study was that we did not additionally assess variables which operationalize motive arousal, motive-related criteria or which could be used to test the predictive validity of the implicit motive measures. A validity criterion-or even better different criteria-could have been used to better evaluate the quality of the implicit motive measures and might have shown quantitative and qualitative differences in their predictive validity (see also paragraph about important future research questions below). Another critical methodological aspect might be that the data collectionparticipants filled in two complex questionnaires twicewas challenging for the participants and might have lead to fatigue or to not taken the data creation seriously. However, the reliabilities and intercorrelations of the explicit motive measures were as expected, which speaks in favor of the overall quality of the data. Third, our results are based on one sample of University students who differ from other populations in terms of age and level of education. Furthermore, participants belong to one cultural group and there might be cultural differences in motive content to different PSE pictorial cues (Hofer 2010). Future research is needed to replicate the intercorrelation patterns in other samples (e.g., participants with different levels of education and from different cultures) to show the generalizability of the results.

\section{Further thoughts}

Keeping in mind that our results are for one thing unexpected and for another thing only based on a single study, our following speculations and thoughts about the overall picture of the correlational analyses have to be taken with care. It seems that the full restriction of the response format of an implicit motive measure produces some overlap with explicit motive measures. The MMG with its restricted response format shares more variance with the PRF, the MET, and the goal measure than the OMT with its halfopen response pattern and the PSE with its open response format. Furthermore, the OMT and PSE showed higher correlations with each other (especially when the same scoring system was used) than with the MMG. We assume that the open and partly open response formats of PSE and OMT allow for "operant behavior", in the terminology of McClelland (1980; McClelland et al. 1989), which is the typical form in which implicit motives are expressed. The clearly-structured and restricted response format of the MMG (agree or disagree with items) might partly evoke "respondent behavior" (which is associated with explicit motives) although the pictures may have evoked implicit motives. The test authors describe the grid technique as "semi-projective" (e.g., Schmalt 1999) and our analyses suggest that it might also be "semi-implicit" (or "semiexplicit"), meaning that it lies in between the typical concepts of implicit and explicit motives (see also discussion of dichotomy of implicit and explicit motives below).

The restriction of the MMG response format was developed as an attempt to enhance the objectivity and reliability of the implicit motive measure. Furthermore, it simplifies the time-consuming scoring procedure of analyzing the content of written material and thus makes it more attractive to use the concept of implicit motives in research.

However, our results suggest that (besides motive arousal through pictorial stimuli) the response format must be at least partly open in order to capture the nature of pure implicit motives without enrichment through conceptual knowledge. If the key to pure implicit motive measurement lies in the openness of the response format allowing for operant response behavior, then standardized automated coding procedures might help to simplify the content coding procedure. An approach which based on the assumption that implicit motives are reflected in the frequency of specific words within PSE-stories, has recently been suggested by Schultheiss (2013). The author used a method to automatically count different word categories (LIWC, Pennebaker et al. 2001) and demonstrated the convergent, discriminant, and predictive validity of this procedure in two studies. However, the hope and fear components were not differentiated in these studies. Thus, 
if researchers are interested in hope and fear, the MMG (which easily assesses hope and fear components by summing up agreements to corresponding items) (for studies approving MMG validity with regard to hope and fear, see for example, Gable 2006; Langens and Schmalt 2002; Langens and Schüler 2005; Puca et al. 2006; Schüler 2007) or the OMT (which allows to distinguish into hope and fear components) might be the methods of choice.

Our study inspired us to ask several questions for future research and further discussion. We believe that the following two questions are the most interesting and important ones. Our first question is: Could another reason for the low statistical overlap between the PSE, OMT, and MMG be that they cover different aspects of implicit motives? Arousing implicit motives (using pictorial stimuli in the three measures) has a broad variety of affective, cognitive, and self-regulatory consequences. The PSE, OMT, and MMG might predict different variables differently well. For example, more open formats (PSE, OMT) might better predict affective consequences, while more respondent formats (MMG) may better predict cognitive processes. Measures stimulating the identification with a main character (OMT) might predict more self-regulatory outcomes, and measures that do not (PSE, MMG) might predict more incentive-driven outcomes. In a similar vein, the three implicit motive measures might be moderated by different explicit motive measures or context variables. Thus, a broader variety of context, moderator, and outcome variables in future studies might help to answer this question and to unravel the unique contribution of each implicit motive measure.

Theoretically, another reason for the partial overlap between implicit and explicit motive measures could be that implicit and explicit motives are not two distinct categories, but lie on a continuum between unconsciously and consciously represented motives. Therefore, our second question is: Why should implicit and explicit motives be dichotomous although consciousness itself is not? Motive research may tend to oversimplify by categorizing into either implicit or explicit motives. The MMG with its "semi-implicit" character would represent such an intermediate position perfectly. It partly arouses implicit processes by the displayed pictures and simultaneously triggers cognitive reflective explicit processes by the verbal statements which have to be rated.

Furthermore, and maybe most importantly, implicit motive research would benefit from defining clear criteria that indicate the (degree of) implicitness of a measure. A first attempt was introduced by De Houwer and colleagues who suggested testing (a) whether the outcome is causally produced by the psychological attribute it was designed to measure, (b) the nature of the processes by which the attribute causes the outcome, and (c) whether these processes operate automatically (De Houwer et al. 2009, p. 347). Future research is needed which evaluate the implicit character of the PSE, MMG and OMT by using De Houwer et al.'s (2009) (or other) criteria of implicitness and combining them with traditional criteria of implicit motive measures such as McClelland et al.'s (1989) prompt that participants had to rate other persons feelings, thoughts and behavior rather than making self-attributions.

\section{Conclusions for future research}

We know that our paper has limitations (which we have outlined above) and that it is only a first attempt to address the issue of (lacking) convergent validity of implicit motive measures. However, we think that this has to be discussed in implicit motive research and hopefully can encourage future research with the correlational pattern between implicit motive measures presented in this paper.

We feel that the reader might want to read a clear recommendation for one (or more) motive measures at the end of this paper in order to get rid of the unsatisfactory feeling that the paper so far raises more questions than it answers. We regret that we might not be able to satisfy the readers' interest in this regard due to the following reasons. Without doubt, the PSE is the best-in terms of proofs of its validity-implicit motive measure in the current literature. However, it is still suboptimal, especially because of the high expertise and high amount of time needed for motive scoring. Furthermore, as already mentioned in the introduction, the current PSE scoring systems are unable to capture the important differentiation into hope and fear components of implicit motives at all (such as Winter's scoring system) or focus on hope and fear components of just one motive (such as Uleman's 1972; Veroffs 1957; Heckhausen's 1963a, b or Birney et al.'s 1969 scoring systems). If a researchers aims to measure the hope and fear components of all three motives, he or she has to learn and make use of three different scoring systems, which is very time-consuming. These disadvantages of the PSE disencourage researchers to engage in implicit motive research which in turn hinders a creative and critical scientific process which is needed for scientific advancements in any research field. The development of simplified, theoretically-based measures of implicit motives which additionally allows to differentiate into hope and fear components is essential. The OMT and MMG are certainly not optimal PSE alternatives yet (especially due to the relatively small number of studies showing their validity so far), but they are a big step towards the aim to facilitate implicit motive assessment. Rather than presenting a clear recommendation for one motive measure, we would like to encourage researchers to participate in the (further) 
development of existing or new implicit motive measures. Categorically rejecting theoretically well-based implicit motive measures such as the OMT and MMG would mean to throw the baby out with the bath water. More in accordance with the sense of science is to conduct future studies which fill the methodological gaps such as studies testing the validity (e.g., in terms of sensitivity towards motive arousal and predictive validity) of implicit motive measures and report data about their validity (including studies that do not confirm their validity, that is reporting null results). Our final conclusion is that a broader basis of empirical evidence is needed before (more satisfying) clear recommendations towards and against existing implicit motive measures can be given.

\section{References}

Andrews, J. O. W. (1967). The achievement motive and advancement in two types of organization. Journal of Personality and Social Psychology, 6, 163-168.

Atkinson, J. W., \& Birch, D. (1970). The dynamics of action. New York: Wiley.

Atkinson, J. W., Heyns, R. W., \& Veroff, J. (1954). The effect of experimental arousal of the affiliation motive on thematic apperception. Journal of Abnormal and Social Psychology, 49, 405-410.

Atkinson, J. W., \& Walker, E. L. (1958). The affiliation motive and perceptual sensitivity to faces. In J. W. Atkinson (Ed.), Motives in fantasy, action, and society: A method of assessment and study (pp. 360-366). Princeton, NJ: Van Nostrand.

Aydinli, A., Bender, M., Chasiotis, A., Cemalcilar, Z., \& van de Vijver, F. R. J. (2014). When does self-reported prosocial motivation predict helping? The moderating role of implicit prosocial motivation. Motivation and Emotion, 38, 645-658. doi:10.1007/s11031-014-9411-8.

Baumann, N., Kaschel, R., \& Kuhl, J. (2005). Striving for unwanted goals: stress-dependent discrepancies between explicit and implicit achievement motives reduce subjective well-being and increase psychosomatic symptoms. Journal of Personality and Social Psychology, 89(5), 781-799.

Baumann, N., Kazén, M., \& Kuhl, J. (2010). Implicit motives: A look from personality systems interaction theory. In O. C. Schultheiss \& J. C. Brunstein (Eds.), Implicit motives (pp. 375-403). New York, NY: Oxford University Press. doi:10.1037/0022-3514.89. 5.781 .

Baumann, N., \& Scheffer, D. (2010). Seeing and mastering difficulty: The role of affective change in achievement flow. Cognition and Emotion, 24, 1304-1328.

Biernat, M. (1989). Motives and values to achieve: Different constructs with different effects. Journal of Personality, 57, 69-95.

Birney, R. C., Burdick, H., \& Teevan, R. C. (1969). Fear of failure. New York: Van Nostrand-Reinhold Company.

Brunstein, J. C. (2008). Implicit and explicit motives. In J. Heckhausen \& H. Heckhausen (Eds.), Motivation and action (pp. 227-246). Cambridge: Cambridge University Press.

Brunstein, J. C., \& Maier, G. W. (2005). Implicit and self-attributed motives to achieve: Two separate but interacting needs. Journal of Personality and Social Psychology, 89, 205-222.
Brunstein, J. C., \& Schmitt, C. H. (2004). Assessing individual differences in achievement motivation with the implicit association test. Journal of Research in Personality, 38, 536-555.

Brunstein, J. C., Schultheiss, O. C., \& Grässmann, R. (1998). Personal goals and emotional well-being: The moderating role of motive dispositions. Journal of Personality and Social Psychology, 75(2), 494-508.

Busch, H., Hofer, J., Chasiotis, A., \& Campos, D. (2013). The achievement flow motive as an element of the autotelic personality: Predicting educational attainment in three cultures. European Journal of Psychology of Education, 28, 239-254. doi:10.1007/s10212-012-0112-y.

Chasiotis, A., \& Hofer, J. (2003). Die Messung impliziter Motive in Deutschland, Costa Rica und Kamerun [Measurement of implicit motives in Germany, Costa Rica, and Cameroon]. Research report to the German Research Foundation (DFG).

De Houwer, J., Teige-Mocigemba, S., Spruyt, A., \& Moors, A. (2009). Implicit measures: A normative analysis and review. Psychological Bulletin, 135, 347-368.

deCharms, R., Morrison, H., Reitman, W., \& McClelland, D. C. (1955). Behavioral correlates of directly and indirectly measured achievement motivation. In D. C. McClelland (Ed.), Studies in motivation (pp. 414-423). New York: Appleton-Century Crofts.

Deci, E. L., \& Ryan, R. M. (1985). Intrinsic motivation and selfdetermination in human behaviour. New York: Plenum.

Esters, F. (2006). Eifersucht bei bildlich dargestellter sexueller und emotionaler Untreue [Jealousy in response to pictures arousing sexual and emotional infidelity]. Unpublished thesis, University of Wuppertal.

Fodor, E. M., Wick, D. P., \& Hartsen, K. M. (2006). The power motive and affective response to assertiveness. Journal of Researach in Personality, 40, 598-610.

Gable, S. L. (2006). Approach and avoidance social motives and goals. Journal of Personality, 74, 175-222.

Gable, S. L., Reis, H. T., \& Elliot, A. J. (2003). Evidence for bivariate systems: An empirical test of appetition and aversion across domains. Journal of Research in Personality, 37, 349-372.

Greenwald, A. G., McGhee, D. E., \& Schwartz, J. L. (1998). Measuring individual differences in implicit cognition: The implicit association test. Journal of Personality and Social Psychology, 74, 1464-1480.

Hagemeyer, B., \& Neyer, F. J. (2012). Assessing implicit motivational orientations in couple relationships: The Partner-Related Agency and Communion Test (PACT). Psychological Assessment, 24, 114-128.

Heckhausen, H. (1963a). Hoffnung und Furcht in der Leistungsmotivation [Hope and fear components of achievement motivation]. Meisenheim am Glan: Anton Hain.

Heckhausen, H. (1963b). Hoffnung und Furcht in der Leistungsmotivation [Hope and fear in achievement motivation]. Meisenheim/Glan: Hain.

Heckhausen, J., \& Heckhausen, H. (2008). Motivation and action. Cambridge: Cambridge University Press.

Heyns, R. W., Veroff, J., \& Atkinson, J. W. (1958). A scoring manual for the affiliation motive. In J. W. Atkinson (Ed.), Motives in fantasy, action, and society (pp. 205-218). Princeton, NY: Van Nostrand.

Hofer, J. (2010). Research on implicit motives across cultures. In O. C. Schultheiss \& J. C. Brunstein (Eds.), Implicit motives (pp. 433-466). New York: Oxford University Press.

Hofer, J., \& Chasiotis, A. (2003). Congruence of life goals and implicit motives as predictors of life satisfaction: Cross-cultural implications of a study of Zambian male adolescents. Motivation and Emotion, 27, 251-272.

Hofer, J., Chasiotis, A., \& Campos, D. (2006). Congruence between social values and implicit motives: Effects on life satisfaction 
across three cultures. European Journal of Psychology, 20, 305-324.

Hurley, J. R. (1955). The Iowa Picture Interpretation Test: A multiple-choice variation of the TAT. Journal of Consulting Psychology, 19(5), 372-376. doi:10.1037/h0040550.

Jackson, D. (1984). Personality research form manual. Port Huron, MI: Research Psychologists Press.

Jemmott, J. B. (1987). Social motives and susceptibility to disease: Stalking individual differences in health risks. Journal of Personality, 55, 267-298.

Job, V., Langens, T. A., \& Brandstätter, V. (2009). Effects of achievement goal striving on well-being: The moderating role of the explicit achievement motive. Personality and Social Psychology Bulletin, 35, 983-996.

Job, V., Oertig, D., Brandstätter, V., \& Allemand, M. (2010). Discrepancies between implicit and explicit motivation and unhealthy eating behavior. Journal of Personality, 78, $1209-1238$.

Kazén, M., \& Kuhl, J. (2011). Directional discrepancy between implicit and explicit power motives is related to well-being among managers. Motivation and Emotion, 35, 317-327. doi:10. 1007/s11031-011-9219-8.

Kehr, H. M. (2004). Implicit/explicit motive discrepancies and volitional depletion among managers. Personality and Social Psychology Bulletin, 30(3), 315-327.

Koole, S. L., \& Jostmann, N. B. (2004). Getting a grip on your feelings: Effects of action orientation and external demands on intuitive affect regulation. Journal of Personality and Social Psychology, 87, 974-990. doi:10.1037/0022-3514.87.6.974.

Kuhl, J. (1999). Der Motiv-Umsetzungs-Test (MUT) [The motiveenactment-test (MUT)]. Unpublished questionnaire, University of Osnabrück, Osnabrück, Germany.

Kuhl, J. (2001). Motivation und Persönlichkeit. Interaktionen psychischer Systeme [Motivation and personality. Interaction between psychological systems]. Göttingen: Hogrefe.

Kuhl, J., \& Scheffer, D. (1999). Der operante multi-motive-test (OMT): Manual [The operant multi-motive-test (OMT): Manual]. Germany: University of Osnabrück.

Kuhl, J., Scheffer, D., \& Eichstaedt, J. (2003). Der Operante MotivTest (OMT): Ein neuer Ansatz zur Messung impliziter Motive [The operant motive test (OMT): A new approach to the assessment of implicit motives]. In F. Rheinberg \& J. Stiensmeier-Pelster (Eds.), Diagnostik von Motivation und Selbstkonzept (pp. 129-149). Göttingen: Hogrefe.

Langan-Fox, J., \& Canty, J. M. (2010). Implicit and self-attributed affiliation motive congruence and depression: The moderating role of perfectionism. Personality and Individual Differences, $49,600-605$

Langens, T. A. (2003). Potential costs of goal imagery: The moderating role of fear of failure. Imagination, Cognition and Personality, 23, 27-44.

Langens, T. A., \& Dorr, S. (2006). Fear of failure and sensitivity to emotional faces. Unpublished data, University of Wuppertal, Germany.

Langens, T. A., \& Schmalt, H.-D. (2002). Emotional consequences of positive daydreaming: The moderating role of fear-of-failure. Personality and Social Psychology Bulletin, 12, 1725-1735.

Langens, T. A., \& Schmalt, H.-D. (2009). Motivational traits: new directions and measuring motives with the Multi-Motive-Grid (MMG). In G. J. Boyle, G. Mattheus, \& D. H. Sakofske (Eds.), Personality theory and assessment (pp. 523-544). London: Sage.

Langens, T. A., \& Schüler, J. (2005). Written emotional expression and emotional well-being: The moderating role of fear-ofrejection. Personality and Social Psychology Bulletin, 31, 818-830.
Lewin, K. (1935). A dynamic theory of personality: Selected papers. New York: McGraw-Hill.

McAdams, D. P., \& Constantian, C. A. (1983). Intimacy and affiliation motives in daily living: An experience sampling analysis. Journal of Personality and Social Psychology, 45, 851-861.

McAdams, D. P., \& Vaillant, G. E. (1982). Intimacy motivation and psychosocial adjustment: A longitudinal study. Journal of Personality Assessment, 46, 586-593.

McClelland, D.C. (1965). N achievement and entrepreneurship: A longitudinal study. Journal of Personality and Social Psychology, 1(4), 389-392.

McClelland, D. C. (1979). Inhibited power motivation and high blood pressure in men. Journal of Abnormal Psychology, 88, 182-190.

McClelland, D. C. (1980). Motive dispositions: The merits of operant and respondent measures. In L. Wheeler (Ed.), Review of personality and social psychology (Vol. 1, pp. 10-31). Beverly Hills: Sage.

McClelland, D. C. (1985). Human motivation. Glenview, IL: Scott, Foresman.

McClelland, D. C. (1995). Achievement motivation in relation to achievement-related recall, performance, and urine flow, a marker associated with release of vasopressin. Motivation and Emotion, 19, 59-76.

McClelland, D. C., Atkinson, J. W., Clark, R. A., \& Lowell, E. L. (1953). The achievement motive. New York: Appleton-CenturyCrofts.

McClelland, D. C., Davidson, R. J., \& Saran, C. (1980). Stressed power motivation, sympathetic activation, immune function, and illness. Journal of Human Stress, 6(2), 11-19.

McClelland, D. C., \& Franz, C. E. (1992). Motivational and other sources of work accomplishment in mid-life: A longitudinal study. Journal of Personality, 60, 679-707.

McClelland, D. C., Koestner, R., \& Weinberger, J. (1989). How do self-attributed and implicit motives differ? Psychological Review, 96(4), 690-702.

McClelland, D. C., Patel, V., Stier, D., \& Brown, D. (1987). The relationship of affiliative arousal to dopamine release. Motivation and Emotion, 9, 1-9.

Morgan, C. D., \& Murray, H. A. (1935). A method for investigating fantasies: The Thematic Apperceptive Test. Archives of Neurological Psychiatry, 34, 289-306.

Murray, H. A. (1938). Explorations in personality. New York: Wiley.

Murray, H. A. (1943). Thematic apperceptive test manual. Cambridge: Harvard University Press.

Pennebaker, J. W., Francis, M. E., \& Booth, R. J. (2001). Linguistic inquiry and word count (LIWC): LIWC2001. Mahwah, NJ: Lawrence Erlbaum Associates.

Puca, R. M. (2005). The influence of the achievement motive on probability estimates in pre- and post-decisional action phases. Journal of Research in Personality, 39, 245-262.

Puca, R. M., Rinkenauer, G., \& Breidenstein, C. (2006). Individual differences in approach and avoidance movements: How the avoidance motive influences response force. Journal of Personality, 74(4), 979-1014.

Puca, R. M., \& Schmalt, H. D. (1999). Task enjoyment: A mediator between achievement motives and performance. Motivation and Emotion, 23, 15-29.

Quirin, M., Düsing, R., \& Kuhl, J. (2013a). Implicit affiliation motive predicts correct intuitive processing. Journal of Individual Differences, 34(1), 24-31.

Quirin, M., Gruber, T., Kuhl, J., \& Düsing, R. (2013b). Is love right? Prefrontal resting brain asymmetry is related to the affiliation motive. Frontiers in Human Neuroscience, 7, 902. doi:10.3389/ fnhum.2013.00902. 
Scheffer, D. (2005). Implizite Motive [Implicit motives]. Göttingen: Hogrefe.

Scheffer, D., Eichstaedt, J., Chasiotis, A., \& Kuhl, J. (2007). Towards an integrated measure of need affiliation and agreeableness derived from the operant motive test. Psychology Science, 49, 308-324.

Scheffer, D., Kuhl, J., \& Eichstaedt, J. (2003). Der Operante Motiv-Test (OMT): Inhaltsklassen, Auswertung, psychometrische Kennwerte und Validierung [The operant motive test (OMT): Contents, scoring, psychometric values, and validation]. In J. StiensmeierPelster \& F. Rheinberg (Eds.), Diagnostik von Motivation und Selbstkonzept (pp. 151-167). Göttingen: Hogrefe.

Schmalt, H. D. (1999). Assessing the achievement motive using the Grid Technique. Journal of Research in Personality, 33, 109-130.

Schmalt, H.-D. (2006). Waist-to-hip ration and female physical attractiveness: The moderating role of power motivation and the mating context. Personality and Individual Differences, 41, 455-465.

Schmalt, H. D., \& Langens, T.A. (1996). Projective, semi-projective, and self-report measures of human motivation predict private cognitive events: striving, memories, and daydreaming. Unpublished manuscript, University of Wuppertal.

Schmidt-Atzert, L. (2004). OLMT. Objektiver Leistungsmotivationstest [Objective Achievement Motivation Test]. Moedling: Schuhfried.

Schnelle, J., Brandstätter, V., \& Knöpfel, A. (2010). The adoption of approach versus avoidance goals. The role of goal-relevant resources. Motivation and Emotion, 34, 215-229.

Schüler, J. (2007). Arousal of flow-experience in a learning setting and its effects on exam-performance and affect. Zeitschrift für Pädagogische Psychologie, 21, 217-227.

Schüler, J. (2010). Achievement incentives determine the effects of achievement-motive incongruence on flow experience. Motivation and Emotion, 34, 2-14.

Schüler, J., Job, V., Fröhlich, S., \& Brandstätter, V. (2008). A high implicit affiliation motive does not always make you happy. Motivation and Emotion, 32, 231-242.

Schüler, J., Sheldon, K. M., \& Fröhlich, S. M. (2010). Implicit need for achievement moderates the relationship between felt competence and subsequent motivation. Journal of Research in Personality, 44, 1-12.

Schultheiss, O. C. (2008). Implicit motives. In O. P. John, R. W. Robins, \& L. A. Pervin (Eds.), Handbook of personality: Theory and research (3rd ed., pp. 603-633). New York: Guilford.

Schultheiss, O. C. (2013). Are implicit motives revealed in mere words? Testing the marker-word hypothesis with computerbased text analysis. Frontiers in Psychology, 4, 748. doi:10. 3389/fpsyg.2013.00748.

Schultheiss, O. C., \& Brunstein, J. C. (2001). Assessment of implicit motives with a research version of the TAT: Picture profiles, gender differences and relations to other personality measures. Journal of Personality Assessment, 77, 71-86.

Schultheiss, O. C., \& Brunstein, J. C. (2002). Inhibited power motivation and persuasive communication: A lens model analysis. Journal of Personality, 70, 553-582.

Schultheiss, O. C., \& Brunstein, J. C. (2010). Implicit motives. NY: Oxford University Press.

Schultheiss, O. C., Dargel, A., \& Rohde, W. (2003). Implicit motives and gonadal steroid hormones: Effects of menstrual cycle phase, oral contraceptive use, and relationship status. Hormones and Behavior, 43, 293-301.

Schultheiss, O. C., \& Hale, J. A. (2007). Implicit motives modulate attentional orienting to perceived facial expressions of emotion. Motivation and Emotion, 31(1), 13-24.
Schultheiss, O. C., Liening, S. H., \& Schad, D. (2008). The reliability of a picture story exercise measure of implicit motives: Estimates of internal consistency, retest reliability, and ipsative stability. Journal of Research in Personality, 42, 1560-1571.

Schultheiss, O. C., \& Pang, J. S. (2007). Measuring implicit motives. In R. W. Robins, R. C. Fraley, \& R. Krueger (Eds.), Handbook of research methods in personality psychology (pp. 322-344). New York: Guilford.

Schultheiss, O. C., Wirth, M. M., \& Stanton, S. J. (2004). Effects of affiliation and power motivation arousal on salivary progesterone and testosterone. Hormones and Behavior, 46(5), 592-599.

Schultheiss, O. C., Wirth, M. M., Torges, C. M., Pang, J. S., Villacorta, M. A., \& Welsh, K. M. (2005). Effects of implicit power motivation on men's and women's implicit learning and testosterone changes after social victory or defeat. Journal of Personality and Social Psychology, 88(1), 174-188.

Schultheiss, O. C., Yankova, D., Dirlikov, B., \& Schad, D. J. (2009). Are implicit and explicit motive measures statistically independent? A fair and balanced test using the picture story exercise and a cue-and response-matched questionnaire measure. Journal of Personality Assessment, 91(1), 72-81.

Shipley, T. E., \& Veroff, J. (1952). A projective measure of need for affiliation. Journal of Experimental Psychology, 43, 349-356.

Slabbinck, H., De Houwer, J., \& Van Kenhove, P. (2011). A pictorial attitude IAT as a measure of implicit motives. European Journal of Personality, 25, 76-86.

Smith, C. P., Feld, S. C., \& Franz, C. E. (1992). Methodological considerations: Steps in research employing content analysis systems. In C. P. Smith (Ed.), Motivation and personality: Handbook of thematic content analysis (pp. 515-536). New York: Cambridge University Press.

Sokolowski, K. (1992). Entwicklung eines Verfahrens zur Messung des Anschlußmotivs [The development of a measure for the motive to affiliate]. Diagnostica, 38, 1-17.

Sokolowski, K., Schmalt, H.-D., Langens, T. A., \& Puca, R. M. (2000). Assessing achievement, affiliation, and power motives all at once-The multi-motive grid (MMG). Journal of Personality Assessment, 74, 126-145.

Spangler, W. D. (1992). Validity of questionnaire and TAT measures of need for achievement: Two meta-analyses. Psychological Bulletin, 112, 140-154.

Stumpf, H., Angleitner, A., Wieck, T., Jackson, D. N., \& Beloch-Till, H. (1985). Deutsche Personality Research Form (PRF) [German Personality Research Form (PRF)]. Göttingen: Hogrefe.

Thrash, T. M., Elliot, A. J., \& Schultheiss, O. C. (2007). Methodological and dispositional predictors of congruence between implicit and explicit need for achievement. Personality and Social Psychology Bulletin, 33(7), 961-974.

Uleman, J. S. (1972). The need for influence: Development and validation of a measure, in comparison with need for power. Genetic Psychology Monographs, 85, 157-214.

Veroff, J. (1957). Development and validation of a projective measure of power motivation. Journal of Abnormal and Social Psychology, 54, 1-8.

Wegner, M., Bohnacker, V., Mempel, G., Teubel, T., \& Schüler, J. (2014a). Explicit and implicit affiliation motives predict verbal and nonverbal social behavior in sports competition. Psychology of Sport and Exercise, 15, 588-595. doi:10.1016/j.psychsport. 2014.06.001.

Wegner, M., \& Schüler, J. (2014). The implicit achievement motive and general life stress affect time spent on competitive matches in racquet sports. In C. Mohiyeddin (Ed.), Contemporary topics and trends in the psychology of sports (pp. 153-176). New York: Nova Publishers.

Wegner, M., Schüler, J., \& Budde, H. (2014b). The implicit affiliation motive moderates cortisol responses to acute psychosocial stress 
in high school students. Psychoneuroendocrinology, 48, 162-168. doi:10.1016/j.psyneuen.2014.06.013.

Wegner, M., \& Teubel, T. (2014). The implicit achievement motive predicts match performances and the explicit motive predicts choices for target distances in team sports. International Journal of Sport Psychology, 45, 1-18.

Winter, D. G. (1973). The power motive. New York: The Free Press. Winter, D. G. (1994). Manual for scoring motive imagery in running text. Unpublished instrument, University of Michigan, Ann Arbor.
Winter, D. G. (1999). Linking personality and "scientific" psychology: The development of empirically derived thematic apperception test measures. In L. Gieser \& M. I. Stein (Eds.), Evocative images: The thematic apperception test and the art of projection (pp. 107-124). Washington, DC: American Psychological Association.

Woike, B., Mcleod, S., \& Goggin, M. (2003). Implicit and explicit motives influence accessibility to different autobiographical knowledge. Personality and Social Psychological Bulletin, 29(8), 1046-1055. doi:10.1177/0146167203254504. 